And am always, in consequence, thoroughly willin', To perform in the pages of Nature (M--).

For reasons no longer existing, it was thought inadvisable to include this in the biography, and my note was made roughly in shorthand for my own interest: it is such that I cannot be certain that no proper name was written in full, but otherwise the version is trustworthy.

$$
\text { Yours faithfully, }
$$

\section{Herbert Dingle}

Purley,

Surrey.

\section{Environmental Studies}

SrR,-The current term "environmental studies" would seem to be of use as a general description of the total or some convenient grouping of parts, but, because of the considerable overlap between the various components, unification has been, and is being, pursued in order to systematize further the whole ficld and thereby to aid further study. Perhaps the suggestion of the term "environology", which would refer to closely interrelated and unified studies in geographical, geological, biological and other fields, would be somewhat premature but would at least indicate a desirable target.

The term "environies" is, however, suggested as being immediately applicable to the study of the physics of the environment, an important and substantial part of which should be instrumentation, largely of an electronic nature. The quantitative assessment of environmental features, based on the principles of physies, is an indispensable aid to understanding and unification; it is and would continue to be of paramount importance in environics.

I propose these two terms with some diffidence in viow of your leader on "Neologonumismatology" (Nature, 223, $659 ; 1969)$, and make no claim as to their philological excellence. I suggest, however, that they are brief, euphonious and evocative and, although they may not fill a long established need, will be very useful in the shorthand largely peculiar to the sciences.

\section{Yours faithfully,}

R. V. Sharman

Department of Physics,

Kingston College of Technology,

Penrhyn Road,

Kingston upon Thames.

\section{Human Biology}

SIR,-This year it has become fashionable to talk of human biology as one might talk of physics or philosophy, and the new school of human sciences at Oxford (see Nature, 223, 660; 1969) has encouraged some to see in it a great leap forward. I do wonder, however, what are the concrete gains to bo had from uniting human genetics, human ecology, psychology, and so on. One could always make a first degreo out of human physiology, human geography and human psychology, for example. This does not seem to be the real issue, for human biology is there if you want to do it.

The event of real interest is that the words "human biology" are on so many lips, but quite without any substance to follow. At this university these are commonly the lips of postgraduate students and young lecturers who have just completed at least seven years' training in nothing but biological science. I have questioned a number of them about their behaviour, but at every attempt the substance of human biology evaporates. Clearly the thorn is on the inside and the outward symptom-endless mention of human biology-has, like the word "ouch", no remedial function. In short, the current enthusiasm for human biology may be an inappropriate solution to a problem that is acutely felt but poorly understood.
It is indeed a good idea to facilitate communication between university departments by bringing them closer together, but I am somewhat incredulous where human biology per se is regarded both as an innovation and a programme for action. How can we define human biology? Its essence cannot be obtained when, by distillation, we merely arrive at a series of already existing courses. Nor do I believe that there is a series of hitherto undreamed courses from which this essence could be obtained. The essontialist programme won't do. In a similar way it could be claimed that some whole called human biology emerges greater than the sum of its parts-but of course holism won't do either. It is just a collective noun, and, since both the essence and the whole are such delightfully abstract entities, time and again talk of them has been adopted as a subterfuge. One is quite safe because there is no possibility of concrete consequenco. This subterfuge is easier to grasp than the underlying thorn, but I would suggest the following solution.

Every kind of knowledge, including science, is valuable. But all kinds of knowledge are not valuable in the same way or for the same reason. There is one kind of know. ledge with which we control our physical environment: knowledge about things. But there is also another kind of knowledge about man, and about the spiritual and ethical explorations which make him peculiarly man. There are of course criticisms that can be levelled at this simple distinction-I believe it perpetuates the body-mind fallacy. However, it is apt enough in the face of the behaviourist's assertion that Freud and Shakespeare are useless because their work is unamenable to operational definition.

The new school of human sciences at Oxford came into being on the recommendation of an inter-faculty committee representing the Boards of Biology and Agricultural Sciencos, Medicine, Social Studies, Anthropology and Geography and Psychology. These sciences have come in recent years to deal, quite deliberately, with man as thing. And yet I think one student betrayed what it was he really wanted when he (erroneously) described the Oxford experiment as a union of arts and science.

It is a curiosity about man that cannot be pursued within the axioms of the biological sciences. Science, like a waggish boy, can be brought into the study of manindeed, the study of man would be quite incomplete without this. But I cannot take at all seriously attempts at the reverse, and such an attempt is not particularly well concealed in any advocacy of human biology. It is of course common to attempt neither-which results, even at its best, in an unsatisfactory dualism. The hobbies of scientists listed in Who's Who are always entertaining and frequently surprising.

\section{Yours faithfully,} Antony Courtice

School of Biological Sciences, University of Sydney.

\section{University News}

Dr J. O. L. King, faculty of veterinary science, has been awarded the status and title of professor at the University of Liverpool.

The title of professor of urology has been conferred on Mr J. P. Blandy, in respect of his post at the London Hospital Medical College, University of London.

Dr E. L. Blair has been appointed to a personal chair in physiology at the University of Newcastle upon Tyne. Dr C. Ellenby has been appointed to a personal chair of zoology at the University of Newcastle upon Tyne.

Mr T. G. Miller, formerly University College of Rhodesia, has been appointed visiting professor in the department of geography at the University of Reading. 